\title{
INSPIRASI BATIK TAMARIND DARI CERITA RAKYAT
}

\author{
BELINDA Sukapura DeWI, ARLETI M. APIN, ARIESA PANDANWANGI, Nuning DAMAYANTI
}

Received: 12 April 2021; Accepted: 20 Mei 2020; Published: 30 Juni 2020

Ed. 2021; 4 (2): 269 - 275

\begin{abstract}
Batik is known not only for its beauty, but also for the values it contains. This potential is very inspiring and gives an idea visualized into batik storytelling using the cold method of tamarin paste, a new approach that is more environmentally friendly. This technique has also been tested both domestically and abroad and has great potential for opportunities batik development with new ideas. An opportunity to preserve batik novelty that have no potential harass to traditional batik. This study applies the discussion of visual language to folklore theme batik works. In the earlier times, speech was common culture carried by elders to their children or grandchildren. Folktales in the form of legends, myths and fables are moral messages way conveyed in a friendly, fun but also educating with devotion. The theories and methods used to discuss two batik samples are taken from folklore which contains educational moral values. Based on a study of selected samples of batik works, it is known that the images or shapes on batik use the Space Time Flat (RWD) and Naturalist Perspective Moment Opname (NPM) systems simultaneously. Most of the depictions of motifs and shapes in batik still use the RWD system, although some forms also use NPM.
\end{abstract}

Keywords: Tamarind batik, folklore, inspiration, visual language, FSM (Flat Space Moment).

\section{PENDAHULUAN}

Perkembangan informasi, teknologi turut mendorong di bidang budaya, salah satunya di dunia batik. Begitu banyak sumber gagas yang dapat diakses melalui media elektronik, tentu saja hal ini membawa dua sisi baik maupun yang kurang baik. Perlu kesadaran serta tanggung jawab penuh menganggapi atau bekerja di ranah ini, bila ditangani secara sembrono maka akan mendatangkan hasil yang merugikan. Motif batik tradisi selayaknya tidak diperlakukan secara asal (APIN, 2020), karena begitu banyak nilai yang belum tuntas tergali, bilamana motif tersebut diacak, menjadikannya sulit untuk menelusuri nilai utuh. Jadi dalam rangka melestarikan batik dapat dilakukan pengolahan ide yang tidak berkaitan dengan motif batik tradisi. Selain itu juga dalam pengembangan batik kebaruan ini digunakan teknik berbeda agar keaslian batik tradisi tak terusik

Proses kreatif dalam batik bercerita berawal dari ide yang menggugah rasa estetik, kemudian digambarkan ke dalam sketsa sebagai pencarian dan studi rupa mengenai cerita rakyat (DEWI, 2020). Cerita rakyat ini diimplementasikan di atas kain menggunakan media Lilin dingin. Media ini merupakan inovasi baru dari lilin panas, yang ramah lingkungan. Hal ini merupakan salah satu bentuk dukungan terhadap pelestarian 
lingkungan hidup jangka panjang.

Kreatifitas merupakan potensi yang dimiliki setiap manusia, oleh karena itu dalam menciptakan karya seni, setiap seniman mempunyai cara atau metoda untuk mewujudkannya. Cara tersebut digunakan dari multi pencarian ide, pemilihan objek, Tema, hingga karya tersebut tercipta (RIYANTI, 2020)

Di dalam proses berpikir kreatif seniman sebenarnya adalah juga suatu ini tahapan mengolah gagasan baru untuk membuat sebuah karya (APIN, 2020)

Sebuah gagasan istimewa sekalipun tak akan menjadi sebuah karya hebat tanpa kemampuan pengolahan yang baik dari seniman, tidak akan bisa tercipta karya seni. Hingga jelas sekali Ide merupakan titik tolak dalam menciptakan karya seni, oleh karenanya ide sangat penting. Ide baru dalam corak atau ragam hias yang bermacam macam dari setiap daerah merupakan hasil dari kreaifitas seniman daerahnya yang mempunyai kekhasan baik dalam motif maupun dari cerita rakyat. Dilihat dari perkembangan corak, batik dibedakan dari ragam hias klasik (tradisional) dan ragam hias saat ini (kontemporer). Batik tradisional yang sering kita lihat, banyak sekali mengangkat budaya daerah, sehingga apa yang dituangkan ke dalam karya mencerminkan keadaan daerahnya. Keunikan batik terletak pada corak/motifnya yang mengandung arti, sehingga apabila membicarakan batik tradisional akan sama dengan berbicara tentang nilai yang terkandung di dalamnya (PARMONO, 2013). Kearifan lokal tidak terletak pada motif saja, tetapi pada cerita rakyat yang mengandung nilai-nilai moral yang baik.
Melalui bercerita kepada anak, ikatan emosional dalam keluarga akan terjalin dengan kuat, sehingga mempunyai sisi keunggulan dalam pembinaan moral, untuk mengatasi penurunan nilai moral (PURWANINGSIH, 2012).

\section{METODOLOGI DAN TEORI}

Metode yang digunakan dalam membaca sebuah karya seni batik bercerita memiliki peran penting dalam mengkaji karya tersebut, sehingga dapat dipahami oleh pemerhati. Selain itu, berfungsi sebagai menjadi masukan bagi perupa. Dalam penelitian ini, metode deskriptif digunakan untuk mengkaji batik. Metode ini memiliki 4 tahapan kuatitatif deskripsi: mendeskripsikan apa yang hadir langsung di depan mata pengamat. Secara detil apa adanya benda / bentuk dalam karya tersebut akan digambarkan secara terstruktur. Analisis Formal:

- Tahap analisis formal masih bersifat deskriptif, yaitu dengan menjelaskan serinci mungkin seluruh unsur formal yang ada dalam karya seni batik bercerita. Data di bagian ini akan diakumulasikan dengan bagian pertama untuk memudahkan proses interpretasi. Garis, bentuk, warna dan komposisi dari keseluruhan karya.

- Interpretasi: Pada tahap ini makna yang terkandung dalam karya batik dijelaskan dengan bantuan data yang diperoleh dari deskripsi maupun analisis formal. Bagian ini berguna untuk membatasi daerah interpretasi dan memudahkan pencarian makna serta nilai dari karya batik bercerita tersebut.

- Evaluasi: Bagian ini merupakan tahap terakhir dari seluruh tahapan, yang menarik kesimpulan dari tiga tahap sebelumnya dengan menghubungkan hasil dari ketiga tahap, ciri, pandangan, dan nilai 
yang berkembang pada saat karya seni itu dibuat.

Dalam penelitian ini digunakan hanya deskripsi, analisis formal, dan interpretasi karena tujuan utama dari penelitian ini adalah untuk mengetahui proses kreatif perupa dalam membuat karya batik dengan tema bercerita.

\section{Bahasa Visual}

Penelitian batik bercerita ini menggunakan bahasa visual Primadi Tabrani dalam proses analisisnya, khususnya sistem penggambaran bahasa visual naturalis Prespective-MomentOpname /NPM dan Ruang Waktu Datar atau disingkat RWD (TABRANI, 2009). Bangsa Nusantara amat akrab dengan berbagai ragam bahasa visual, mulai dari bahasa dalam gerak tubuh, tarian, bentuk bangunan, warna, relief, arca, dan banyak lagi. Di antara sekian banyak bahasa rupa atau visual ini salah satu yang diulas dalam tulisan ini adalah bahasa rupa bidang datar.

Sungguh suatu kemampuan mengolah unsur rupa yang teramat tinggi yang dituangkan dalam banyak ragam produk budaya. Berupa batik, ilustrasi, lukisan dinding, dan tentunya dalam batik. Tetapi tidak semua dipaparkan secara gamblang, banyak diantaranya diungkapkan melalui metafora dan simbol. Dengan begitu gaya ungkap yang digunakan amat bervariasi, tiap daerah mempunyai gaya khas yang akrab mereka gunakan, inipun turut memperkaya dalam tampilan bahasa visual yang terdapat dianeka media.

\section{Proses Pembuatan Batik}

Batik berasal dari bahasa Jawa yaitu amba dan nitik yang artinya tulisan dan titik. Batik diawali dari kain putih kemudian digambar, dengan menggunakan lilin panas/lilin yang dicairkan sebagai pembatas mengikuti jejak gambar dari proses sebelumnya. Diawali dari pembuatan terbatas di kalangan kerajaan, batik lalu menyebar juga keluar lingkungan istana. Sejak itulah batik mulai dikenal secara luas dalam lingkungan masyarakat biasa. Hanya ketika itu motif yang digunakan oleh raja dan lingkunagannya diatur penggunaannya, tak boleh sembarang orang memakainya. Atau lebih dikenal dengan istilah; Pakem Batik, aturan ketat dalam motif, warna dan pemakainya. Hal ini diatur karena saat itu batik merupakan penanda visual atau identitas pengguna, juga menyimpan simbol. Perkembangan batik yang dinamis mulai dari teknik, bahan, ragam hias dan pewarnaan sering perkembangan jaman. Masa itu batik hanya di atas kain putih kain mori, namun saat ini batik bisa dibuat dari berbagai jenis kain, seperti sutra, poliester, rayon, dan bahan sintetis lainnya.

\section{Teknik Pasta Tamarind Dingin}

Pembuatannya batik proses dingin menggunakan perintang yang terbuat dari serbuk biji asam Jawa atau tamarind yang dilarutkan dalam air dingin dan ditambah dengan sebagian kecil mentega yang telah dicairkan dengan air panas sebelum dimasukkan ke dalam plastik segitiga (piping bag). Plastik tersebut kemudian diikat menjadi satu dan ujung bagian yang tajam dipotong sedikit untuk mengeluarkan pasta. Ukuran ketebalan garis dapat diatur dengan ukuran potongan pada ujung piping bag, makin besar potongan, makin tebal hasil garis demikin pula sebaliknya. Pengaturan kekentalan pasta amat berpengaruhpada mutu hasil kerja, hal ini terkait jenis kain yang digunakan. Makin tebal kain pasta harus makin cair, berlaku juga sebaliknya. 


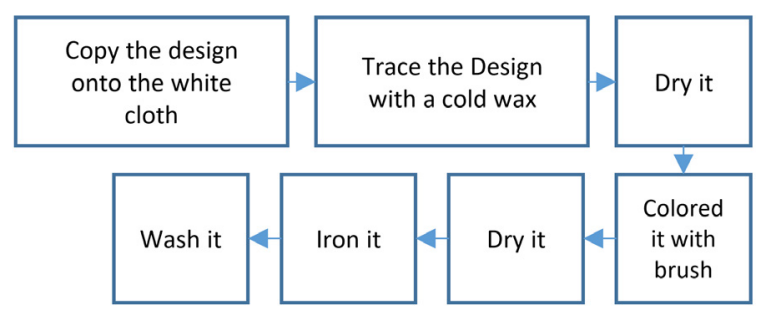

Gambar 1. Proses tahapan Batik teknik tamarind.

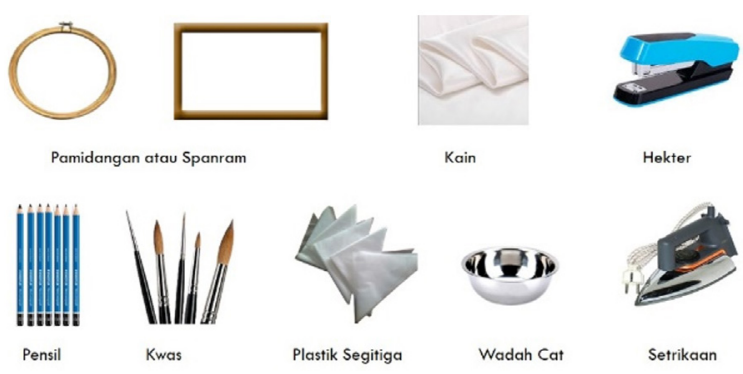

Gambar 2. Alat bantu untuk Batik teknik tamarind. Sumber dokumentasi pribadi.

Motif batik digambar di atas kertas, kemudian sketsa tersebut dipindahkan ke atas kain menggunakan pensil dan sketsa pensil tadi ditimpa dengan pasta tamarind pada sketsa yang dibuat di atas kain putih. Setelah selesai, keringkan kain tersebut, agar pastanya kering. Setelah meresap erat ke dalam serat kain, ketika diwarnai dengan kuas, warna bagian satu dan bagian yang dipisahkan oleh tamarind tidak akan bercampur satu sama lain. Setelah selesai diwarnai, biarkan kain mengering. Langkah selanjutnya adalah menyetrika kain dengan merata, agar warnanya muncul menjadi lebih cerah, selanjutnya batik dicuci dengan air dingin untuk menghilangkan pasta tamarindnya. Setelah semua bekas tamarind hilang, keringkan dan setrika kembali kain tersebut.

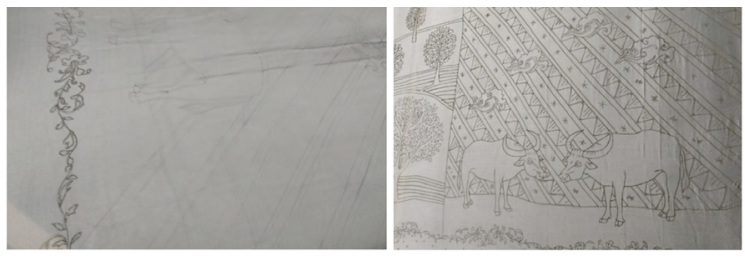

Gambar 3. Sketsa pada kain dan mulai diterapkan garis dengan guta Tamarin. Sumber : dok tim peneliti.
Tahap pewarnaan yang utama dalam teknik ini adalah menggunakan kuas atau colet, proses celup relatif dihindari, karena bila terlalu lama dalam kondisi basah, maka pasta tamarind akan larut dan terkelupas, mengingat bahan dasarnya dilarutkan dengan air. Ini perbedaan yang signifikan dari proses pewarnaan dibandingkan dengan teknik lilin panas.

Oleh karena pewarnaan memakai kuas, maka tidak membutuhkan banyak air, dan ini menghemat pewarna sekaligus hemat air saat pencucian di tahap akhir. Karenanya tidak menimbulkan banyak limbah buangan seperti dalam pencelupan pada batik teknik lilin panas. Hampir semua cairan pewarna yang dioleskan akan diserap oleh kain hingga sedikit sekali sisa yang terbuang.

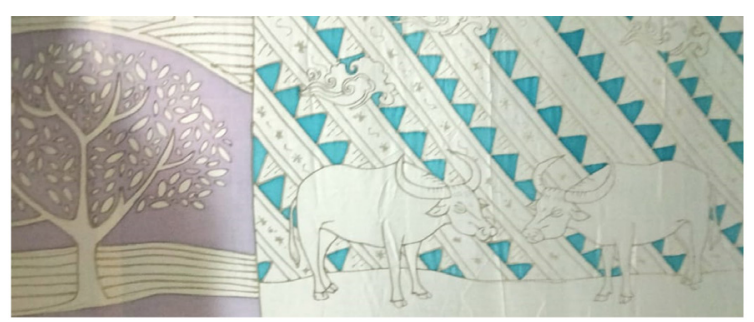

Gambar 4. tahap pewarnaan menggunakan kuas.

Sumber : dok tim peneliti

Secara garis besar, teknik ini relatif lebih mudah, lebih aman dan tidak memerlukan waktu lama dalam pengerjaan. Tidak terlalu banyak menimbulkan limbah karena pewarnaan tidak menyisakan banyak residu hingga mengotori lingkungan. Secara teknis setelah pewarnaan selesai dan kering total, lalu sikukus untuk menguatkan warna, setelah itu dibilas dengan air bersih, keringkan dan selesai semua tahapan kerjanya.

\section{Analisis}

Dalam analisis karya batik bercerita, karya tidak hanya dibaca dengan pendekatan tekstual, tetapi juga melalui pendekatan kontekstual. Teks yang kita kenal berupa tulisan dalam 
berbagai bentuk seperti koran, majalah, buku dll. Dalam karya seni informasi disampaikan dalam bentuk visual melalui unsur-unsur rupa seperti; garis, bidang, warna, tekstur, ruang dan komposisi (keseimbangan, kesatuan, irama).

\section{Burung Gelatik dan Betet}

Cerita rakyat Burung Gelatik dan Betet dibuat

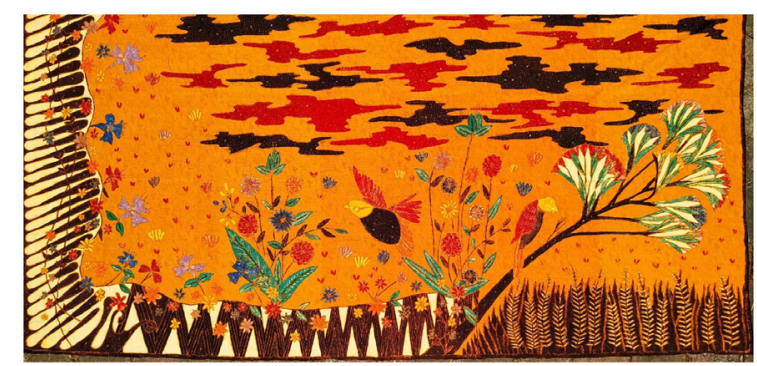

Gambar 5. Burung Gelatik dan Betet karya Belinda S Dewi . Sumber : dok tim peneliti.

menjadi sebuah karya batik di atas sutera berukuran $110 \mathrm{~cm}$ x $210 \mathrm{~cm}$ memiliki warna dasar ochre dengan komposisi yang terdiri dari 3 bagian, yaitu:

- Bagian atas: awan-awan

- Bagian tengah: Burung Betet, Gelatik, pohon, dan bunga-bunga

- Bagian bawah: Bentuk-bentuk geometric segitiga dengan taburan bunga di atasnya serta rumpun daun dan padi.

Pada bagian kiri sisi kain terdapat motif abstrak positif dan negatif dari bentuk abstraksi motif parang yang sudah distilas, bentuk berulang ini memberikan irama yang dinamis. Pada sepanjang sisi kiri kain terdapat dua batang sulur bunga berupa garis yang berkelok dan taburan bunga yang membelah parang-parang, sehingga motifnya parang tidak terlihat kaku.

Awan merah dan hitam mendominasi bagian atas karena hampir setengah dari lebar kain diisi motif awan yang mendominasi langit, seakan akan komposisi awan terlihat lebih berat, sehingga bagian tengah kain yang merupakan bagian utama dari cerita tidak begitu menonjol, karena terkalahkan oleh dominasi langit. Meskipun demikian dominasi langit dapat diimbangi olehbagian bawah dengan motif geometric segi tiga. Kedua burung masih terlihat menonjol sebagai tokoh utama. Badan burung gelatik menggunakan warna hitam dan diberi corak abstrak. Kepalanya berwarna kuning tampak samping dengan sayap yang berwarna merah tampak atas serta ekor yang berwarna oranye. Terdapat rumpun bunga di antara burung gelatik dan burung betet yang sedang hinggap di pohon, bunga dan daun tampak atas dengan posisi keduanya menghadap ke depan, sehingga keduanya digambarkan terpisah. Pohon yang dihinggapi burung betet di bagian kanan mengimbangi motif parang bagian kiri yang berisi motif abstrak, sehingga komposisi menjadi seimbang. Komposisi batik ini terlihat serasi dengan susunan warna yang harmonis.

\section{Batik Bercerita Kancil dan Kera (Kancil yang Cerdik)}

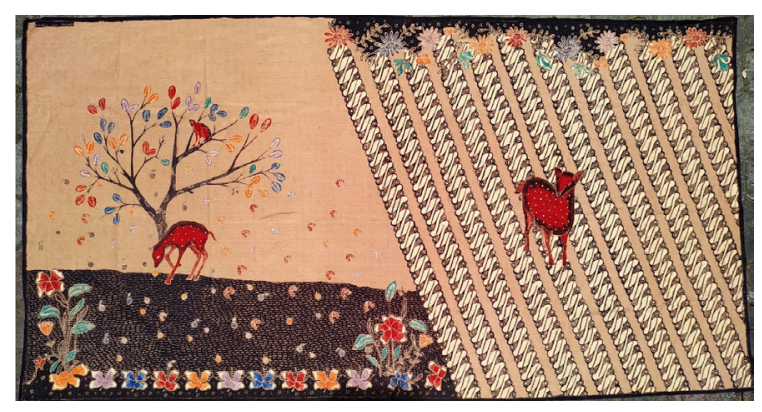

Gambar 6. Batik Bercerita Kancil dan Kera karya Belinda S Dewi. Sumber : dok tim peneliti.

Batik bercerita kancil dan kera digambarkan pada kain suetra baron sepanjang $110 \mathrm{~cm}$ x 220 $\mathrm{cm}$ dengan format batik pagi sore, yaitu batik yang dibagi dua secara diagonal. Pada bagian kanan menggunakan corak batik tradisional dengan posisi motif batik stilasi parang, posisi diagonal dan pada bagian kiri sisa batik diagonal tersebut digambarkan sebuah pohon jambu besar dengan kera sedang berada di atas pohon, bentuk visual yang kontras 
menggambarkan kontrasnya pagi dan sore, penggambaran parang yang sangat masif dan teratur, berbanding terbalik dengan bagian kirinya yang lebih ekspresif pohon dan kancil sedang memungut buah jambu yang dilempar oleh kera dari atas, meskipun keduanya berbeda tapi bila dilihat secara keseluruhan terlihat seimbang. Jambu berserakan di atas tanah berwarna hitam. Pada bagian bawah dari tanah dibatasi oleh deretan kuntum bunga yang diapit oleh rumpun bunga di bagian kiri bawah batik sampai bagian pertengahan. Kuntum bunga diapit oleh rumpun bunga yang berbatasan dengan batik diagonal.

Bagian deretan deretan batik diagonal di bagian kanan terdapat seekor kancil yang cukup besar di bagian tengah. Sepanjang bagian atas corak batik ini terdapat sulur bunga dan komposisi batik secara keseluruhan kontras karena mencerminkan karakter kancil dank kera yang berbeda.kancil pada bagian kiri digambarkan tampak samping atau tampak khas, sedang kaki kancil bagian depan tampak depan, sehingga penggambaran kancil aneka tampak. Penggambaran kancil pada bagian kanan dengan latar belakang batik parang, kancil digambarkan tampak depan agak menyamping dan seluruh penggambarannya dilakukan dengan sistem naturalis moment opname (NPM). Begitupun corak yang digunakan di kedua sisi. Sisi kiri penggambaran pohon lebih dinamis, sedangkan penggambaran motif batik lebih kaku dan statis dengan garis-garis diagonal yang tegas. Komposisi pada bagian kanan lebih berat, tapi dapat diimbangi tanah bagian kiri bawah. Secara keseluruhan batik terlihat serasi dengan paduan warna dasar yang sama, yaitu merah muda.

\section{KESIMPULAN DAN SARAN}

Kesimpulan

Pada batik bercerita dapat dilihat motif maupun bentuk binatang secara visual sebagian besar masih menggunakan sistim Ruang Waktu Datar (RWD), meskipun sebagian kecil masih ada yang menggunakan Naturalis Momen Opname (NPM). Pembuatan karya batik kontemporer di beberapa tempat memberikan angin segar dengan motif dan ragam hias yang baru maupun motif yang berasal dari motif tradisional yang diperbaharui. Perkembangan motif motif baru pada batik kontemporer sangat menarik untuk diamati, karena meskipun pembuatan batik di era sekarang tetapi visualisasinya tetap menawan dan mampu bersaing di masa kini.

\section{Saran}

Upaya untuk turut serta melestarikan batik tanpa merusak nilai tradisi di dalamnya telah terbuka lebar melalui teknik batik tamarind ini. Sumber gagas atau ide yang tersedia juga tak terbatas jumlahnya, sehingga para pengrajin batik dapat memiliki peluang peningkatan ekonomi dengan berkreasi bebas menggunakan teknik tamarind ini sedangkan batik tradisi tetap menggunakan tatacara tradisi hingga tetap terjaga.

\section{DAFTAR PUSTAKA}

ACHJADI, J.

2009. The Exquisite Indonesia. Jakarta:

Dekranas, Equinox Publishing.

APIN, A. M.

2020. THE ROLE OF THE DESIGNER IN FACING THE TRADITIONAL ART AND BATIK INDUSTRY. In Ariani, Art and Design (p. 67). India: Novateur Publication.

APIN, A. M.

2020. The Story of Guriang Tujub in the Batik Work of Guta Tamarin. Reposition of The Art and Cultural Heritage After 
Pandemic Era (pp. 28-29).

Bandung: ISBI.

\section{Arleti M. Apin, B. S.}

2021. Tamarind Batik Semination an Economic

Improvement for Patimban Fisherman inti Crafts ment. In E. Surbakti, The Art of Entrepreneurs to Survive During Pandemic Covid-19 (p. 41). India: Novateur.

\section{CAitLin, $\mathrm{K}$.}

2019. Mindful By Design. UK:

Sage Publication.

Cama Juli Rianingrum, A. P.

2021. ESCALATION OF SOCIETY'S

COMPETITIVENESS:

ESCALATION OF YOUNG

ENTREPRENEURSHIP

COMPETENCE

THROUGH WORKSHOPOF

PROCESSEDTAMARIND ON TOP

OF WASTRA. In M. P. Elisabeth

Surbakti, CommunityService in the Midst of the Covid-19 (pp. 35 -42). India:

Novateur Publication.

\section{DEWI, B. S.}

2020. The Creation Process of Batik with

Storytelling Theme. Reposition of The Art and Cultural Heritage After Pandemic Era (pp. 62-64). Bandung: ISBI.

2011. Batik Dekod. Pekalongan:

Govenrnment of Pekalongan City.

\section{PRAMONO, K}

2013. Nilai Kearifan lokal batik tradisional

Kawung. Filsafat, 134-146.
PuriwaningsiH, E.

2010. Keluarga dalam mewujudkan Pendidikan Nilai sebagai upaya mengatasi degradasi nilai moral. Pendidikan Sosiologi dan Humaniora, 47-48.

\section{RIYANTI, B. P.}

2019. Kreativitas dan Inovasi di Tempat Kerja. Jakarta: Unika Atma Jaya.

\section{TABRANI, P.}

2009. Bahasa Rupa. Bandung: Kelir. 